\title{
A COMPARATIVE STUDY ON EFFECT OF LEMON JUICE WITH LEMON SEEDS VS. LEMON JUICE ALONE ON HIGH SENSITIVITY C-REACTIVE PROTEIN IN SUBJECTS WITH OBESITY UNDERGOING CALORIE RESTRICTION- A PILOT STUDY
}

\author{
Sowmya M11, Raghavendra Rao'2, Sowjanya M³, Poornima4, Vinay P5, Babina NM6, Bindu Shridar ${ }^{7}$, K. Shanmugam ${ }^{8}$
}

${ }^{1}$ Assistant Professor, Department of Nutrition, S-VYASA University, Bengaluru, Karnataka.

${ }^{2} \mathrm{HOD}$, Department of Yoga, HCG Cancer Hospital, Bangalore, Karnataka.

${ }_{3}^{3}$ Senior Resident, Department of Emergency, Columbia Asia Hospital, Mysuru, Karnataka.

${ }^{4} \mathrm{HOD}$, Department of Biotechnology, Tumkur University, Tumakuru, Karnataka.

5 Senior Resident, Department of Dentistry, Sapthagiri Institute of Medical Sciences and Research Institute, Bengaluru, Karnataka.

${ }^{6}$ Professor and HOD, Department of Clinical Yoga, Jindal PG Institute of Naturopathy and Yogic Sciences, Bangalore, Karnataka.

${ }^{7}$ Chief Medical Officer, Nature Cure Hospital, Jayanagar, Bangalore, Karnataka.

${ }^{8}$ Professor, Department of Clinical Naturopathy, Jindal PG Institute of Naturopathy and Yogic Sciences, Bangalore, Karnataka.

\begin{abstract}
BACKGROUND

Obesity or overweight is the most common problem faced by millions of people in this world today. Obesity is a chronic inflammatory lifestyle related disorder that increases the preponderance for many illnesses like coronary heart disease, hypertension, diabetes, cancer etc. Calorie restriction has been shown to reduce weight in obese individuals and confer health benefits. Triterpenoids have hypolipidaemic, anti-obesity, anti-hyperglycaemic and anti-cancerous effect.

In this study, we will evaluate the use of lemon seeds rich in triterpenoids on inflammatory markers in subjects with obesity undergoing calorie restriction.
\end{abstract}

\section{MATERIALS AND METHODS}

This randomised controlled study was conducted on 30 subjects of age between 20 - 60 years for a period of 7 days; were studied by dividing them into two groups; 15 subjects each in intervention and control group respectively.

\section{RESULTS}

All the parameters were compared between 2 groups. After giving lemon seeds Hs-CRP, TG, VLDL, BMI, Weight, WC, HC and WHR had decreased when compared to control group. HDL levels had reduced in both groups.

\section{CONCLUSION}

This study states that lemon seeds extraction, which is rich in triterpenoids is more effective than lemon juice which is rich in vitamin-C.

\section{KEYWORDS}

High Sensitive C-Reactive Protein, Body Mass Index, Waist Circumference, Hip Circumference, Waist-to-Hip Ratio.

HOW TO CITE THIS ARTICLE: Sowmya M, Rao R, Sowjanya M, et al. A comparative study on effect of lemon juice with lemon seeds vs. lemon juice alone on high sensitivity C-reactive protein in subjects with obesity undergoing calorie restriction- a pilot study. J. Evolution Med. Dent. Sci. 2018;7(16):2018-2022, DOI: 10.14260/jemds/2018/454

\section{BACKGROUND}

Obesity or overweight is the most common problem faced by millions of people in this World today. ${ }^{1}$ It is a complex multifactorial condition, in which excess body fat may put a person at health risk. ${ }^{2}$ Increasing evidence suggests that obesity is not a simple problem of will power or self-control, but a complex disorder involving appetite regulation and energy metabolism that is associated with a variety of comorbid conditions. ${ }^{3-6}$ Obesity is a chronic inflammatory lifestyle related disorder that increases the preponderance for many illnesses like coronary heart disease, hypertension, diabetes, cancer etc.

'Financial or Other Competing Interest': None.

Submission 10-03-2018, Peer Review 02-04-2018,

Acceptance 09-04-2018, Published 16-04-2018.

Corresponding Author:

Dr. Sowmya $M$,

\#793, Bogadi $2^{\text {nd }}$ Stage North

Behind Nirmithi Kendra,

Mysore-570026, Karnataka.

E-mail: sowmyaskids@gmail.com

DOI: $10.14260 /$ jemds $/ 2018 / 454$

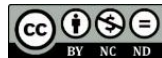

High-sensitivity C-reactive protein (Hs-CRP) levels are closely associated with obesity. ${ }^{7}$ Obesity and insulin resistances portend a significant risk of atherosclerotic disease. ${ }^{8-11}$ Elevated triglycerides, moderate elevations in small dense LDL cholesterol and decreased HDL cholesterol define the atherogenic dyslipidaemia (combined hyperlipidaemia) of insulin resistance.11-14

Calorie restriction has been shown to reduce weight in obese individuals and confer health benefits. In caloric restriction, inflammatory status is decreased by low energy intake that results in less energy supply to immune cells to favour energy saving under calorie restriction. ${ }^{15}$ Lemon seeds are rich in triterpenoids ${ }^{16}$ and they have hypolipidaemic, anti-obesity, anti-hyperglycaemic and anti-cancerous effect.17,18-21 Naturally occurring limonoids in citrus fruits have anti-obesity and anti-hyperglycaemia effects. 18 Supplementation of naturally occurring vitamin $\mathrm{C}$ in higher concentrations does have effect on serum cholesterol levels, that they reduce LDL levels. ${ }^{19}$ The triterpenoids that are present in lemon seeds/ juice have anti-hyperglycaemic and hypolipidaemic effects. ${ }^{20,21}$ Citrus flavonoids and tocotrienols that are present in lemon have effect on serum cholesterol, 
i.e. they reduce blood levels of cholesterol. ${ }^{17}$ It is clinically proven that consumption of diet rich in fruits, vegetables and other naturally derived constituents is associated with lower incidences of chronic diseases, ${ }^{22}$ oxidative stress $^{23}$ and reduced inflammatory levels. ${ }^{24}$ Hence, in the current proposal we were interested to understand the benefit of triterpenoids rich diet in reducing inflammation and cholesterol levels in obese subjects.

\section{MATERIALS AND METHODS \\ Objectives}

To evaluate the effects of intake of lemon juice with lemon seeds extract during calorie restriction on high sensitivity Creactive protein $[\mathrm{Hs}-\mathrm{CRP}]$ obese subjects.

\section{Subjects}

30 subjects of age between 20 - 60 years were participated in this study. They were screened through a routine medical check-up and those satisfying diagnostic criteria for obesity were recruited in this study.

\section{Selection Criteria for Study}

\section{Inclusion Criteria}

1. Age 20-60 yrs.

2. Obese individual with BMI $>25<35$.

3. History of hypercholesterolaemia or dyslipidaemia.

\section{Sample Size $(n=30)$}

Sample size is taken as per our convenience.

\section{Group-1 ( $n=15)$}

Received calorie restricted diet with lemon juice + lemon seeds extraction.

\section{Group-2 ( $n=15)$}

Received calorie restricted diet with lemon juice without lemon seeds extraction.

\section{Study Design}

Randomised controlled study.

\section{Randomisation}

Patients were randomised using computerised randomisation table and were allocated into two groups of 15 each.

\section{Study Intervention Chart}

Total 7 days study plan for each subject in this present study: - Lemon juice with lemon seeds extraction was given only for 5 days and 2 doses had been given in a day (between each dose of $10-12$ hrs. gap had been given) and last 2 days only lemon juice were given according to this study.

Totally, 500 mgs of lemon seeds extraction was given in a day, 250 mgs - 0 - 250 mgs.

\section{Making Lemon Juice}

For one glass of lemon juice: $300 \mathrm{~mL}$ of water +2 teaspoons of lemon juice $+1 / 2$ teaspoon of jaggery are mixed and extra $250 \mathrm{mgs}$ of lemon seeds extraction was added.

\section{Time of Giving Juices}

$8 \mathrm{am}-300 \mathrm{~mL}$ of lemon juice with $250 \mathrm{mgs}$ of lemon seeds extraction.
10 am - only $300 \mathrm{~mL}$ of lemon juice.

$12 \mathrm{am}-300 \mathrm{~mL}$ of lemon juice.

$2 \mathrm{pm}-300 \mathrm{~mL}$ of lemon juice.

$4 \mathrm{pm}-300 \mathrm{~mL}$ of lemon juice.

7:30 pm - $300 \mathrm{~mL}$ of lemon juice with $250 \mathrm{mgs}$ of lemon seeds extraction.

Starting 5 days ( $1^{\text {st }}-5^{\text {th }}$ day $)$ all the subjects are on calorie restricted diet like 1 time fruit diet (like 1 small piece of water melon/ 1 small piece of papaya) was given with lemon juice with lemon seeds extraction. Totally, 6 glasses of lemon juice were given in a day ( 2 glasses with lemon seeds extraction +4 glass of only lemon juice) 3 - 4 litres of water is taken by each subject. Last 2 days ( $6^{\text {th }}-7^{\text {th }}$ day), 2 times fruits diet (like 1 small piece of water melon, 1 small piece of papaya) + only lemon juice without extraction.

\section{Steps in Extraction of Lemon Seeds Extraction}

The lemon seeds are dried in sunlight and powdered by using grinder and extraction unit 2046 and control unit 2046 are used to make lemon seeds extraction and $50-70 \mathrm{~mL}$ of the solvent-ethanol alcohol as be used. After all the following steps, extraction was taken in Petri dish and allowed it to dry for 2 - 3 days.

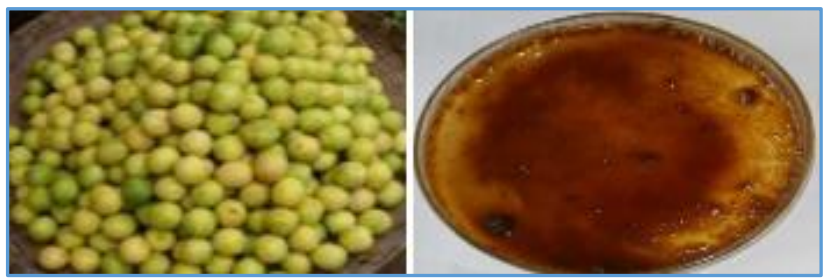

Lemons and Lemon Seeds Extraction

\section{The Extraction Unit 2045 and the Control Unit 2046}

In the extraction unit, solvent extraction was done in two steps. At first, the sample was immersed in the boiling solvent to dissolve most of the soluble material. In the second step, the sample was raised about the solvent surface to permit an efficient washing of the sample with solvent from the condensers. ${ }^{25}$

After extraction, the condenser valves were closed by turning the valve knobs a quarter turn. After some minutes most of the solvent is collected in the condenser. The last residue of solvent was evaporated when the air valves were opened. 25

The control unit controls the temperature of the hot plate. It has timer function for the various extraction procedure steps. ${ }^{25}$

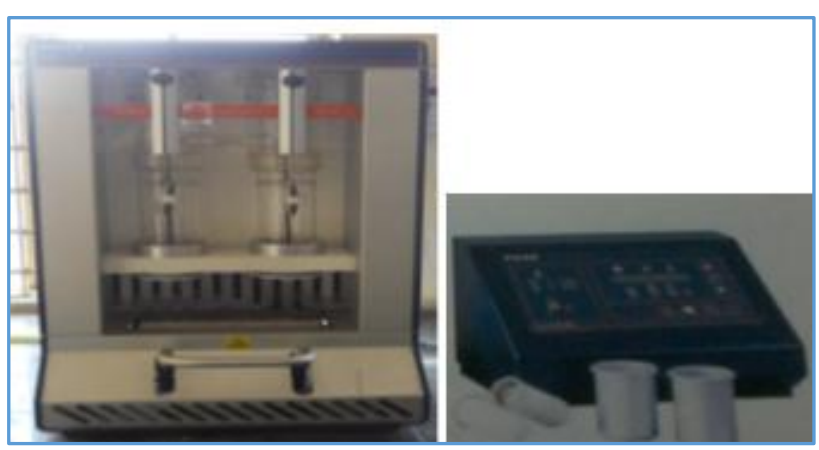

The Extraction Unit 2045 and the Control Unit 2046 


\section{Methods}

Inflammation is measured by Hs-CRP. All the parameters like Hs-CRP and Anthropometry measurements were taken pre ( $1^{\text {st }}$ day) and post ( $8^{\text {th }}$ day) of the intervention.

Blood was drawn from an antecubital vein in the morning after a 12-hour overnight fasting and was sent for analysis within four hours of blood collection. Hs-CRP levels were measured by immunoturbidimetry method by a biochemical autoanalyser at the Central Laboratory, Bengaluru.

Anthropometric measurements were obtained from the complete physical examination. Weight and height were measured with the subject's shoeless and wearing light clothing. BMI was derived from the formula, weight $(\mathrm{kg}) \div$ (height) 2 (m2). With the participant standing, WC was measured midway between the superior iliac crest and the costal margin and hip circumference at its maximum protrusion point of the buttocks around the pelvis, and then the WHR was calculated as a measure of regional fat distribution.

All the data were analysed by SPSS 20.0. Data had been analysed for distribution and normality and appropriate statistics as be used. Test followed had been considered statistically significant if $\mathrm{p}<0.05$.

The following methods of statistical analysis have been used in this study. Continuous data were expressed as mean \pm standard deviation and presented in tables and figures-
1) Paired Wilcoxon's signed rank.
2) Mann-Whitney independent samples test.
3) Test for normality- Shapiro-Wilk.

\section{RESULTS}

All the parameters were compared between 2 groups. There was as significant decreased in Hs-CRP, BMI, weight, WC and HC.

\begin{tabular}{|c|c|c|c|}
\hline Sl. No. & $\begin{array}{c}\text { Hs-CRP } \\
(\mathbf{m g} / \mathbf{d L}) \text { Pre }\end{array}$ & Post & $\begin{array}{c}\text { Hs-CRP } \\
\text { Chn }\end{array}$ \\
\hline $\begin{array}{c}\text { Intervention } \\
\text { Group (n= 15) }\end{array}$ & $0.53 \pm 0.66$ & $0.47 \pm 0.5$ & $0.07 \pm 0.27$ \\
\hline $\begin{array}{c}\text { Control Group } \\
\text { (n= 15) }\end{array}$ & $0.32 \pm 0.28$ & $0.33 \pm 0.33$ & $-0.02 \pm 0.07$ \\
\hline
\end{tabular}

Table 1. Represents Mean Scores of both the Groups on the High Sensitivity C-Reactive Protein (Hs-CRP). Values are Mean \pm Standard Deviation

Hs-CRP = High sensitivity C-reactive protein; Hs-CRP Chn is the difference between pre and post mean value \pm standard deviation.

Hs-CRP $\mathrm{P}=0.426$ as per paired Wilcoxon's signed rank within intervention group.

$\mathrm{P}=0.378$ as per paired Wilcoxon's signed rank within control group.

Hs-CRP $\mathrm{P}=0.267$ as per Mann-Whitney Independent sample test between groups.

Hs-CRP is not significant in this study. In intervention group, the difference between pre and post mean values \pm standard deviation shows that there is decrease in Hs-CRP level in this study, but Hs-CRP level is increased in control group.

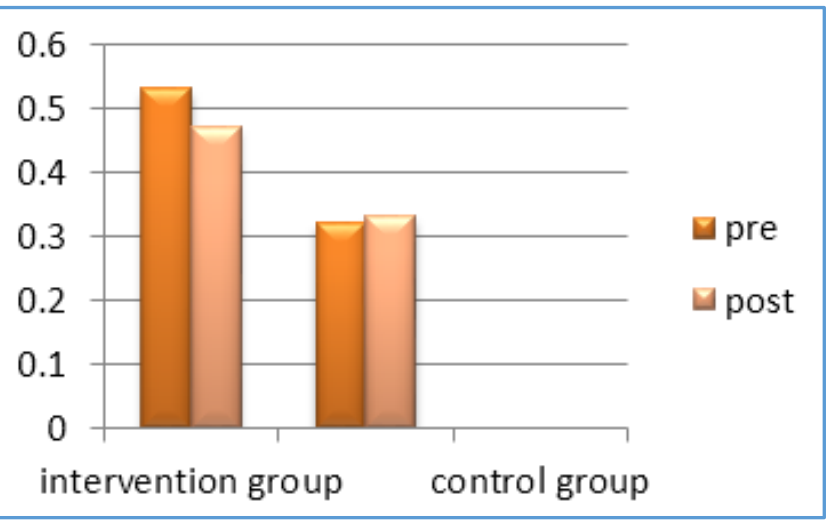

Graph 1. Comparing Hs-CRP in Intervention and Control Groups

This graph shows that Hs-CRP is decreased in intervention group, but in control Hs-CRP is increased.

\begin{tabular}{|c|c|c|c|c|c|c|}
\hline Sl. No. & $\begin{array}{c}\text { BMI } \\
\text { Pre }\end{array}$ & Post & $\begin{array}{c}\text { BMI } \\
\text { Chn }\end{array}$ & $\begin{array}{c}\text { Weight } \\
\text { (kg) } \\
\text { Pre }\end{array}$ & Post & $\begin{array}{c}\text { Weight } \\
\text { Chn }\end{array}$ \\
\hline $\begin{array}{c}\text { Intervention } \\
\text { Group }\end{array}$ & $\begin{array}{c}29.5 \pm \\
3.2\end{array}$ & $27.5 \pm$ & $2.0 \pm$ & $72.5 \pm$ & $67.6 \pm$ & $4.92 \pm$ \\
0.4 & 9.4 & 8.8 & 1.0 \\
\hline Control & $28.2 \pm$ & $26.8 \pm$ & $1.4 \pm$ & $67.9 \pm$ & $64.6 \pm$ & $3.3 \pm$ \\
Group & 3.09 & 3.17 & 3.2 & 8.86 & 9.03 & 0.7 \\
\hline
\end{tabular}

Table 2. Represents Mean Scores of both the Groups on

Anthropometric Measurements like BMI and Weight. Values are Mean \pm Standard Deviation

BMI= Body Mass Index.

For BMI $\mathrm{P}=0.001$, for Weight $\mathrm{P}=0.001$ as per paired Wilcoxon's signed rank within intervention group.

For BMI $\mathrm{P}=0.001$ for Weight $\mathrm{P}=0.001$ as per paired Wilcoxon's signed rank within control group.

BMI $\mathrm{P}=0.0001$, Weight $\mathrm{P}=0.0001$ as per Mann-Whitney Independent sample test between groups.

BMI and Weight are highly significant in this study. BMI and Weight mean value \pm standard deviation shows that there is decrease in both groups.

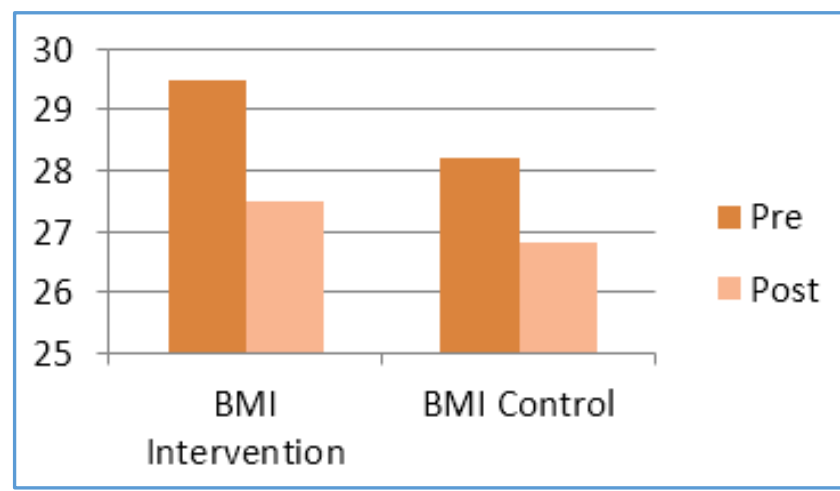

Graph 2. Comparing BMI in Intervention and Control Groups

This graph shows that BMI is decreased in both groups after giving intervention. 


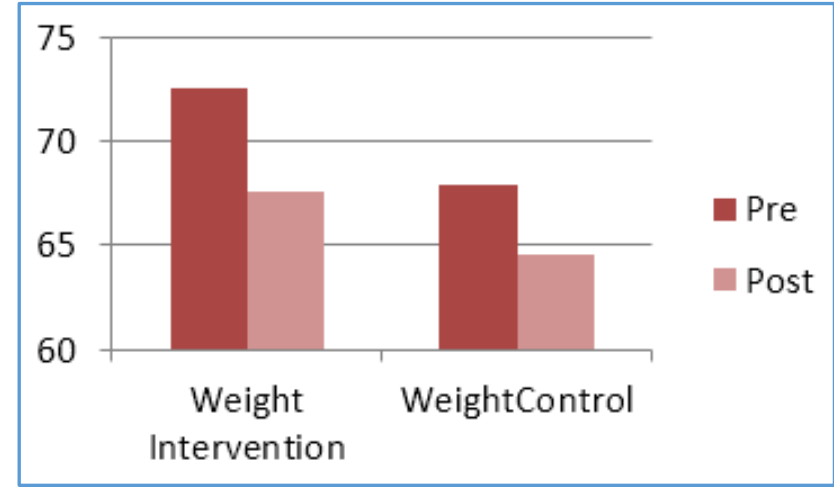

Graph 3. Comparing Weight in Intervention and Control Groups

This graph shows that BMI is decreased in both groups after giving intervention.

\begin{tabular}{|c|c|c|c|c|c|c|}
\hline Sl. No. & $\begin{array}{c}\text { WC } \\
\mathbf{( c m )} \\
\text { Pre }\end{array}$ & Post & $\begin{array}{c}\text { WC } \\
\text { Chn }\end{array}$ & $\begin{array}{c}\text { HC }(\mathbf{c m}) \\
\text { Pre }\end{array}$ & Post & $\begin{array}{c}\text { HC } \\
\text { Chn }\end{array}$ \\
\hline $\begin{array}{c}\text { Intervention } \\
92.2 \pm\end{array}$ & $80.9 \pm$ & $11.27 \pm$ & $105.8 \pm$ & $95.2 \pm$ & $3.53 \pm$ \\
Group & 14.5 & 13.2 & 3.37 & 8.39 & 8.3 & 25.0 \\
\hline Control & $87.5 \pm$ & $79.4 \pm$ & $8.03 \pm$ & $108.3 \pm$ & $99.1 \pm$ & $2.0 \pm$ \\
Group & 13.04 & 12.4 & 2.43 & 8.36 & 8.16 & 29.4 \\
\hline
\end{tabular}

Table 3. Represents Mean Scores of both the Groups on the WC and HC. Values are Mean \pm Standard Deviation

WC $=$ Waist Circumference, $\mathrm{HC}=$ Hip Circumference.

For $\mathrm{WC} \mathrm{P}=0.001$, for $\mathrm{HC} \mathrm{P}=0.001$, for as per paired Wilcoxon's signed rank within intervention group.

For $\mathrm{WC} \mathrm{P}=0.001$, for $\mathrm{HC} \mathrm{P}=0.001$, for as per paired Wilcoxon's signed rank within control group.

WC $\mathrm{P}=0.004, \mathrm{HC} \mathrm{P}=0.004$ as per Mann-Whitney Independent sample test between groups.

WC is highly significant in this study, but WC and HC mean value \pm standard deviation shows that there is decrease in both groups.

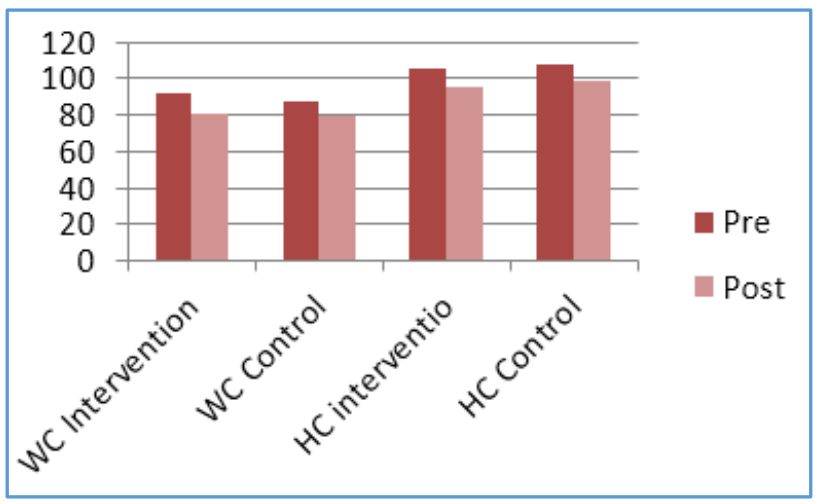

Graph 4. Comparing WC and HC in Intervention and Control Groups

This graph shows that WC and HC is decreased in both groups after giving intervention.

\begin{tabular}{|c|c|c|c|}
\hline Sl. No. & WH Ratio Pre & Post & WH Ratio Chn \\
\hline $\begin{array}{c}\text { Intervention } \\
\text { Group (n=15) }\end{array}$ & $0.86 \pm 0.1$ & $0.84 \pm 0.1$ & $0.02 \pm 0.04$ \\
\hline $\begin{array}{c}\text { Control Group } \\
\text { (n=15) }\end{array}$ & $0.8 \pm 0.08$ & $0.79 \pm 0.09$ & $0.01 \pm 0.29$ \\
\hline
\end{tabular}

Table 4. Represents Mean Scores of both the Groups on the WH Ratio. Values are Mean \pm Standard Deviation

WHR= Waist-to-hip circumference ratio .

For WHR $\mathrm{P}=0.123$ as per paired Wilcoxon's signed rank within intervention group,

For WHR $\mathrm{P}=0.096$ as per paired Wilcoxon's signed rank within control group.

WHR $\mathrm{P}=0.389$ as per Mann-Whitney independent sample test between groups.

WHR mean value \pm standard deviation shows that there is decrease in both groups.

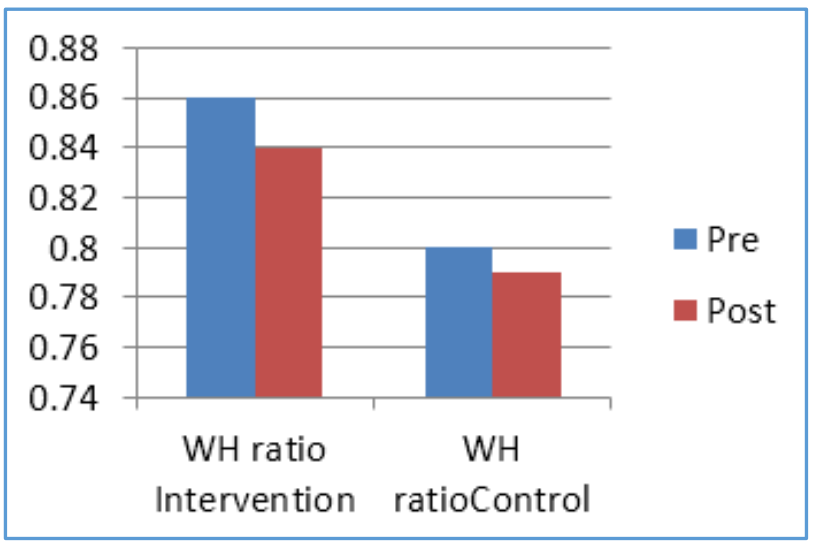

Graph 5. Comparing WH Ratio in Intervention and Control Groups

This graph show that WHR is slightly decreased in both groups after giving intervention.

\section{DISCUSSION}

In this study, Hs-CRP level is reducing slightly. The present study is done in less subjects for shorter duration, so this study shows that Hs-CRP is not significant, but pre and post mean value \pm standard deviation of Hs-CRP difference value of $0.0695 \pm 0.27327$ is decreased and this value is nearing to significant value, Hs-CRP results are compared with A. Salminen 2008 and Jin Hee Kim 2011 who suggested that terpenoids are suppressing the process of inflammation. ${ }^{26,27}$ In the present study inflammation marker result is same as A. Salminen and Jin Hee Kim study results on inflammation. Weight is significantly decreased and weight results are compared with Koji Nagao 2010, who had suggested that citrus auraptene given it for 4 weeks had decreased in TG levels and weight. The present study results of weight is same as Kiji Nagao results. BMI, WC and HC are significantly decreased in this study and WHR is not significant.

\section{Limitation}

In this study the sample size is low and it is taken as per our convenience not estimated scientifically. 


\section{CONCLUSION}

The present study concluded that 7 days of lemon juice with lemon seeds extract, with calorie restriction has significantly decreased Hs-CRP, BMI, weight, waist circumference, hip circumference and WHR in overweight or obese subjects.

\section{REFERENCES}

[1] Harrison TR. Harrison's Principles of internal medicine. 18 ${ }^{\text {th }}$ edn. McGraw-Hill 2012: p. 629.

[2] Lyznicki JM, Young DC, Riggs JA, et al. Obesity: assessment \& management in primary care. Am Fam Physician 2001;63(11):2185-96.

[3] National Institutes of Health, National Heart, Lung and Blood Institute. Clinical Guidelines on the identification, evaluation and treatment of overweight and obesity in adults-the evidence report. Obes Res 1998;6(Suppl 2): S51-S209.

[4] Barlow SE, Dietz WH. Obesity evaluation and treatment: expert committee recommendations. The Maternal and Child Health Bureau, Health Resources and Services Administration and the Department of Health and Human Services. Pediatrics 1998;102(3):E29.

[5] Dickey RA, Bray GA. American Association of Clinical Endocrinologists, American College of Endocrinology. AACE/ACE position statement on the prevention, diagnosis and treatment of obesity. Endocrine Practice 1998;4(5):297-350.

[6] Thomas PR. Weighing the options: Criteria for evaluating weight-management programs. Committee to Develop Criteria for Evaluating the Outcomes of Approaches to Prevent and Treat Obesity, Institute of Medicine. Washington DC: National Academy Press (US), 1995.

[7] Blaha MJ, Rivera JJ, Budoff MJ, et al. Association between obesity, high-sensitivity C-reactive protein $\geq 2$ $\mathrm{mg} / \mathrm{L}$ and subclinical atherosclerosis: implications of JUPITER from the Multi-Ethnic Study of Atherosclerosis. Arterioscler Thromb Vasc Biol 2011;31(6):1430-8.

[8] Rutter MK, Meigs JB, Sullivan LM, et al. Insulin resistance, the metabolic syndrome and incident cardiovascular events in the Framingham Offspring Study. Diabetes 2005;54(11):3252-7.

[9] Racette SB, Evans EM, Weiss EP, et al. Abdominal adiposity is a stronger predictor of insulin resistance than fitness among 50-95 year olds. Diabetes Care 2006;29(3):673-8.

[10] Meigs JB, Wilson PW, Fox CS, et al. Body mass index, metabolic syndrome and risk of type 2 diabetes or cardiovascular disease. J Clin Endocrinol Metab 2006;91(8):2906-12.

[11] Bloomgarden ZT. Insulin resistance, dyslipidemia and cardiovascular disease. Diabetes Care 2007;30(8):2164-70.
[12] Veerkamp MJ, De Graaf J, Stalenhoef AF. Role of insulin resistance in familial combined hyperlipidemia. Arterioscler Thromb Vasc Biol 2005;25(5):1026-31.

[13] Brunzell JD. Clinical practice. Hypertriglyceridemia. N Engl J Med 2007;357(10):1009-17.

[14] Krauss RM, Blanche PJ, Rawlings RS, et al. Separate effects of reduced carbohydrate intake and weight loss on atherogenic dyslipidemia. Am J Clin Nutr 2006;83(5):1025-31.

[15] Wang H, Ye J. Regulation of energy balance by inflammation: common theme in physiology and pathology. Rev Endocr Metab Disord 2015;16(1):4754.

[16] Sporn MB, Liby KT, Yore MM, et al. New synthetic triterpenoids: potent agents for prevention and treatment of tissue injury caused by inflammatory and oxidative stress. J Nat Prod 2011;74(3):537-45.

[17] Roza JM, Xian-Liu Z, Guthrie N. Effect of citrus flavonoids and tocotrienols on serum cholesterol levels in hypercholesterolemia subjects. Altern Ther Health Med 2007;13(6):44-8.

[18] Ono E, Inoue J, Hashidume T, et al. Anti-obesity and anti-hyperglycemic effect of the dietary citrus limoniod, nomilin in mice fed a high diet. Biochem Biophys Res Commun 2011;410(3);677-81.

[19] Jacques PF, Sulsky SI, Perrone GE, et al. Effect of vitamin $C$ supplemention on lipo protein cholesterol, apolipoprotein and triglyceride concentrations. Ann Epidemiol 1995;5(1):52-9.

[20] Khan Y, Khan RA, Afroz S, et al. Evaluation of hypolipidemic effect of citrus lemon. J Basic \& Appl Sci 2010;6(1):39-43.

[21] Samuel P, Shalchi OB. Effect of vitamin C on serum cholesterol in patients with hypercholesterolemia \& arteriosclerosis. Circulation 1964;29:24-5.

[22] Block G, Patterson B, Subar A. Fruits, vegetables and cancer prevention: a review of the epidemiological evidence. Nutrition and Cancer 1992;18(1):1-29.

[23] Prior RL. Fruits and vegetables in the prevention of cellular oxidative damage. Am J Clin Nutr 2003;78(Suppl 3):570S-8S.

[24] O'Keefe JH, Gheewala NM, O'Keefe JO. Dietary strategies for improving post-prandial glucose, lipids, inflammation and cardiovascular health. J Am Coll Cardiol 2008;51(3):249-55.

[25] FOSS-Soxtec ${ }^{\mathrm{TM}} 2045$. Extraction Unit User Manual 1001.1992/ Rev.2. Page no 3-5.

[26] Salminen A, Lehtonen M, Suuronen $T$, et al. Terpenoids: natural inhibitors of NF- $\mathrm{BB}$ signaling with anti-inflammatory and anticancer potential. Cellular and Molecular Life Sciences 2008;65(19):2979-99.

[27] Kim JH, Patil BS, Jayaprakasha GK, et al. Antiinflammatory properties of citrus limonoids and their isolation and characterization. Dec 2011. 